\title{
Engineered nanomaterials and crops: physiology and growth of barley as affected by nanoscale cerium oxide
}

\author{
Alessandro Mattiello, ${ }^{1}$ Filip Pošćić, ${ }^{1}$ Guido Fellet, ${ }^{1}$ Costanza Zavalloni, ${ }^{1,2}$ Marta Fontana, ${ }^{1}$ \\ Barbara Piani, ${ }^{1}$ Massimo Vischi, ${ }^{1}$ Fabiano Miceli, ${ }^{1}$ Rita Musetti, ${ }^{1}$ Luca Marchiol${ }^{1}$ \\ ${ }^{1}$ Department of Agriculture, Food, Environment and Animal Sciences, University of Udine, Italy; \\ ${ }^{2}$ Agriculture Studies Department, California State University Stanislaus, One University Circle, \\ Turlock, CA, USA
}

\begin{abstract}
In recent years, remarkable progress has been made in developing nanotechnology. This has led to a fast-growth of commercial applications, which involve the use of a great variety of manufactured nanomaterials. Given that, soils and sediments are the ultimate sinks of engineered nanomaterials (ENMs), they can be taken up by microorganisms, nematodes, earthworms or plants, and potentially transferred to the food chain up to animals and humans. However, the reactions of the biota exposed to ENMs of different size are still not well under-
\end{abstract}

Correspondence: Alessandro Mattiello, Department of Agriculture, Food, Environment and Animal Sciences (DI4A), University of Udine, via delle Scienze 208, I-33100 Udine, Italy.

E-mail: alessandro.mattiello@uniud.it

Key words: Cerium oxide nanoparticles; barley; germination; plant growth.

Acknowledgements: the authors would like to acknowledge Anastasios Papadiamantis for technical assistance in the use of the Brunauer-EmmettTeller (BET) method and the Environmental Nanoscience research group at Birmingham University (UK) for the access to the lab facilities. We also wish to thank Giorgio Angelo Lucchini (Dipartimento di Scienze Agrarie e Ambientali - Produzione, Territorio, Agroenergia, Università degli Studi di Milano, Italy) for ICP-MS analysis.

Funding: this work was supported by a project funded by DISA - Department of Agriculture and Environmental Sciences, University of Udine, through Grant n.64 dd. 08-09.2014 (RANDOLPH - Relazioni tra nanoparticelle metalliche e piante superiori).

Conflict of interest: the authors declare no potential conflict of interest.

Conference presentation: SIA XLIV Congress, Bologna, 2015.

Received for publication: 1 December 2015.

Revision received: 22 April 2016.

Accepted for publication: 27 April 2016.

(C) Copyright A. Mattiello et al., 2016

Licensee PAGEPress, Italy

Italian Journal of Agronomy 2016; 11:725

doi:10.4081/ija.2016.725

This article is distributed under the terms of the Creative Commons Attribution Noncommercial License (by-nc 4.0) which permits any noncommercial use, distribution, and reproduction in any medium, provided the original author(s) and source are credited. stood. Very few studies on nanoparticles-plant interactions have been published, so far. In this paper we report the results of multiple experiments carried out to study the effects of cerium oxide nanoparticles $\left(n \mathrm{CeO}_{2}\right)$ on Hordeum vulgare. The $n \mathrm{CeO}_{2}$ powder and suspension were characterised for specific surface area, z-average size, and zeta potential. Germinating caryopses and barley seedlings were exposed to an aqueous dispersion of $n \mathrm{CeO}_{2}$ at respectively $0,500,1000$ and $2000 \mathrm{mg}$ $\mathrm{L}^{-1}$. Data on root elongation, mitotic index and cerium concentration in seedlings were collected. Plants of barley were grown to physiological maturity in soil enriched with respectively 500 and $1000 \mathrm{mg} \mathrm{kg}^{-1}$ of $n \mathrm{CeO}_{2}$. We reported that seed germination was not affected by the $n \mathrm{CeO}_{2}$, however, signals of genotoxicity were evidenced by mitotic index coupled with a shortage of root elongation. In the life-cycle experiment although no toxicity symptoms were detected, we demonstrated that barley growth was affected by $n \mathrm{CeO}_{2}$.

\section{Introduction}

The dramatic expansion of nanotechnology is based on the application of the unique properties of engineered nanomaterials (ENMs) to different industrial sectors. Also agriculture is expected to receive strong innovation by nanotechnology to increase global food security, particularly in the perspective of climate change (Dasgupta et al., 2015). On the other side, ENMs are considered as emerging contaminants and there is significant concern about their fate throughout the biosphere (Richardson and Ternes, 2011; Lowry et al., 2012). According to the U.S. Environmental Protection Agency (USEPA), ENMs are grouped into the following categories: carbon-based materials, metal-based materials, dendrimers, and composites (USEPA, 2007). The metal-based ENMs are typically characterised by a very high surface reactivity due to their small size $(<100 \mathrm{~nm})$. This will have two important consequences that may need special consideration: i) the interactions of ENMs with the surrounding matrix are largely unknown; and ii) a potential high attitude to pass across biological membranes.

Very little are known about ENMs fluxes and their accumulation in soil, surface water, and groundwater, which were identified as ENMs receptors (Keller et al., 2013). Currently, challenges and questions are being raised since it cannot be claimed whether fluxes of ENMs through the primary sector are fully safe for human health and the environment.

Cerium (Ce) is the most abundant of the rare earth elements (REE) in the Earth's crust, where it ranks about 26 in abundance $(0.0046 \%$ by weight) among other components. The abundance of Ce in soil varies from 15.8 to $97.4 \mathrm{mg} \mathrm{kg}^{-1}$, with a mean of $48.7 \mathrm{mg} \mathrm{kg}^{-1}$ (Salminen et al., 2005). In the last years, Ce-based compounds have received much 
attention because of their popular applications as $\mathrm{CeO}_{2}$ nanoparticles $\left(n \mathrm{CeO}_{2}\right)$ in industrial applications. Unfortunately, due to the relative newness of $n \mathrm{CeO}_{2}$ environmental chemistry, the impact of $n \mathrm{CeO}_{2}$ on ecosystem health (e.g., toxicological effects on aquatic-terrestrial organisms) has not been well understood yet (Collin et al., 2014). Even if the role and toxicity of REEs to plants have yet been clarified, it was demonstrated that low concentrations of bulk REEs may promote growth and biomass yield of several crops (Tyler, 2004). Zhao et al. (2012) more recently confirmed that the uptake of cerium compounds, might affect positively the plant nutritional status.

So far, the studies devoted to elucidate the fate and effects of $n \mathrm{CeO}_{2}$ on higher plants have not been extensive. In fact, most of the work was carried out in hydroponics and provided contradictory results. Ma et al. (2010) verified that the germination of cabbage, canola, cucumber, lettuce, radish, tomato and wheat was unaffected by $2000 \mathrm{mg} \mathrm{L}^{-1}$ of suspension. The root elongation observed on the same species was unaffected by $n \mathrm{CeO}_{2}$ with the only exception of lettuce (-34\%). LópezMoreno et al. (2010) showed that germination of alfalfa, corn, cucumber and soybean were enhanced at lower concentrations of $n \mathrm{CeO}_{2}(500$ and $1000 \mathrm{mg} \mathrm{L}^{-1}$ ) but were inhibited up to $30 \%$ at $2000-4000 \mathrm{mg} \mathrm{L}^{-1}$. Root growth was significantly promoted by $n \mathrm{CeO}_{2}$ in cucumber and corn but reduced in alfalfa and tomato. Almost at all concentrations, $n \mathrm{CeO}_{2}$ promoted shoot elongation in the studied species. Zhang et al. (2011) reported a concentration-dependent sorption of $n \mathrm{CeO}_{2}$ to exposed cucumber roots to 7 and $25 \mathrm{~nm} n \mathrm{CeO}_{2}$. Finally, Wang et al. (2003) provide the first evidence on the trans-generational impact of $n \mathrm{CeO}_{2}$ on the growth and development of tomato plants exposed to low concentration $\left(10 \mathrm{mg} \mathrm{L}^{-1}\right)$ of $n \mathrm{CeO}_{2}$.

Studies in more realistic conditions than hydroponics were carried out growing plants on soil amended with $n \mathrm{CeO}_{2}$. Priester et al. (2012) firstly reported data regarding the effects of $n \mathrm{CeO}_{2}$ on soybean grown to full maturity in $n \mathrm{CeO}_{2}$-enriched soil. Although plant growth and yield were modestly reduced and Ce root to shoot translocation was negligible, nitrogen fixation was severely disrupted. Subsequently, a more detailed study on the inhibition of bacterial nitrogen fixation in soybean was carried by Hernández-Viezcas et al. (2013). Rico et al. (2013) demonstrated that rice grown in a soil amended with $500 \mathrm{mg} \mathrm{kg}^{-1}$ of $n \mathrm{CeO}_{2}$-produced grains with an altered nutritional value with respect to the control plants. Similar results were observed on cilantro (Morales et al., 2013) and wheat (Rico et al., 2014).

In this paper we present an overview of the studies on the effects of $n \mathrm{CeO}_{2}$ on the growth of Hordeum vulgare $\mathrm{L}$. that is ranked in the top 5 cereals in the world (FAOSTAT, 2014). Experimental observations were carried out with the following aims: i) to investigate the impact of $n \mathrm{CeO}_{2}$ on plant growth; ii) plant physiology; iii) to evaluate the $\mathrm{Ce}$ uptake and translocation in plant fractions; and iv) to observe changes in the nutritional properties of barley grains.

\section{Materials and methods}

\section{Nanoparticle characterisation}

Cerium (IV) oxide nanopowder was purchased from Sigma-Aldrich Corp. (St. Louis, M0, USA; product ID 544841). Particle characterisation was carried out at the Facility for Environmental Nanoscience Analysis and Characterisation (FENAC), University of Birmingham (UK). The specific surface area of the $n \mathrm{CeO}_{2}$ was measured by the Brunauer-Emmett-Teller method by using the Surface Area and Pore Size Analyser SA 3100 plus (Beckman Coulter, Inc., Brea, CA, USA). The $n \mathrm{CeO}_{2}$ suspension was characterised for z-average size, measured as hydrodynamic diameter, and zeta potential, via electrophoretic mobility by dynamic light scattering (DLS) method using the Nano ZS90 (Malvern Instruments Ltd., Malvern, Worcestershire, UK).

Size distribution of suspended $n \mathrm{CeO}_{2}$ was measured as relative absorption and weight by differential centrifugal sedimentation (DCS) method by using the DC24000 (Analytik Ltd., Cambridge, UK). The height distribution of the $n \mathrm{CeO}_{2}$ suspension was measured by atomic force microscopy (AFM). The analyses were carried out using a PSIA XE-100 (Park System Corp., Suwon, South Korea) in non-contact mode. The diameter distribution was analysed by transmission electron microscopy (TEM) with the use of a 1200EX microscope (JEOL Ltd., Tokyo, Japan) operating at $80 \mathrm{kV}$.

\section{Laboratory trials}

\section{Seed germination and root elongation}

Caryopses of spring barley ( $H$. vulgare L. var. Tunika), provided by S.I.S. Società Italiana Sementi (San Lazzaro di Savena, Bologna, Italy) were sterilised (70\% ethanol and 5\% sodium hypochlorite) and then rinsed six times with sterilised water. All caryopses were transferred in sterile conditions into Petri dishes soaked with distilled water (Ctrl), $500,1000,2000 \mathrm{mg} \mathrm{L}^{-1} n \mathrm{CeO}_{2}$ suspensions and 500, 1000, $2000 \mathrm{mg} \mathrm{L}^{-1}$ of $\mathrm{CeNO}_{3}$. The Petri dishes were taped and placed in the dark at $21^{\circ} \mathrm{C}$ for $3 \mathrm{~d}$. The germination percentage was calculated as the ratio of germinated seeds out of the total seeds. Barley seedlings of another set of caryopses, which received the same treatments for $7 \mathrm{~d}$ were used to evaluate root elongation and Ce uptake. Root elongation was calculated as the average length and the sum of all roots emerged from each seed. The root length measurements were made with Image $\mathbf{J}$ software (Schneider et al., 2012).

\section{Mitotic index}

An additional set of caryopses germinated in distilled water with actively growing roots of at least $2.5 \mathrm{~cm}$ in length were placed on Petri dishes and exposed to $500,1000,2000 \mathrm{mg} \mathrm{L}^{-1} n \mathrm{CeO}_{2}$ suspensions for 24 h. Ten root tips per each treatment, prepared according to Aksoy and Deveci (2012), were studied to evaluate possible genotoxic effects of $n \mathrm{CeO}_{2}$. According to Mattiello et al. (2015), each treatment was replicated three times, for a total of about 10,000 cell observations. The mitotic index (MI) was evaluated as the percentage of dividing cells out of the total number of scored cells.

\section{Greenhouse trial}

\section{Soil characterisation}

The soil used for this study was collected in Udine, Italy ( $46^{\circ} 04^{\prime} 52^{\prime \prime}$ $\mathrm{N}, 13^{\circ} 12$ ' $33^{\prime \prime} \mathrm{E}$; top $20 \mathrm{~cm}$ ), air dried at room temperature and sieved through a $2 \mathrm{~mm}$ mesh prior to characterisation. The soil was classified as clay soil (sand $26 \%$, silt $6.4 \%$ and clay $67.6 \%$ ) with $\mathrm{pH} 7.4 \pm 0.01$, water holding capacity (WHC) $53.7 \%$, cation exchange capacity 13.9 $\mathrm{cmol} \mathrm{kg}^{-1}$ dry matter (DM), electrical conductivity $1235 \mu \mathrm{s}^{-1} \mathrm{~cm}^{-1}$ and organic matter $4.4 \%$.

\section{Nanoparticle addition to soil}

The Ce nanopowder was added to the clay soil before sowing plants. Two mixtures of soil and $n \mathrm{CeO}_{2}$ were prepared according to Priester $e t$ al. (2012) to obtain the final $n \mathrm{CeO}_{2}$ concentration of 500 and $1000 \mathrm{mg}$ $\mathrm{kg}^{-1}$, respectively. The $n \mathrm{CeO}_{2}$-enriched soils were stored in the dark at $10^{\circ} \mathrm{C}$ for two weeks. After the equilibration, five $4 \mathrm{~L}$ polyethylene pots (height $18 \mathrm{~cm}, \emptyset 18 \mathrm{~cm}$ ) per treatment were filled with the control and nanoparticles amended soil for a total of 15 pots. The control treatment received no nanoparticle amendment. 


\section{Plant growth}

Seeds of spring barley (H. vulgare L., cv. Tunika) were sown in pots containing the $n \mathrm{CeO}_{2}$-enriched soils and the control treatment. Then the pots were placed in a semi-sealed greenhouse. Two weeks after seed planting, seedlings were thinned to two seedlings per pot. During the growth period, the pots were watered twice a week to maintain soil at $60 \%$ WHC. Plants were harvested at physiological maturity. Plant shoots were severed at the collar and separated into stems, leaves, spikes, and grains. Leaf area was measured using a LI-3100C Area Meter (Li-Cor Corp., Lincoln, NE, USA). The plant fractions were oven dried at $105^{\circ} \mathrm{C}$ for $24 \mathrm{~h}$ and weighed.

\section{Measurement of photosynthesis by infrared gas analysis}

The photosynthetic rate at saturating light intensity (Amax, $\mu$ mol $\left.\mathrm{CO}_{2} \mathrm{~m}^{-2} \mathrm{~s}^{-1}\right)$ and transpiration rate $\left(\mathrm{mmol} \mathrm{H}_{2} \mathrm{O} \mathrm{m}^{-2} \mathrm{~s}^{-1}\right)$ were measured with a LI-6400 portable gas exchange system (Li-Cor Corp.) on the youngest fully expanded leaf of three individual plants per treatment. The measurements were carried out between 9 and $14 \mathrm{~h}$ allowing leaves to reach the steady state in the following conditions: PAR 1200 $\mu \mathrm{mol} \mathrm{m}{ }^{-2} \mathrm{~s}^{-1}, \mathrm{CO}_{2} 400 \mathrm{ppm}$ and $25^{\circ} \mathrm{C}$.

\section{Characterising $n \mathrm{CeO}_{2}$ distribution in plant tissues}

To assess the possible uptake of the $n \mathrm{CeO}_{2}$ from culture medium to the root tissues and the translocation to the diverse parts of the plantlets, ultrastructural analyses on root, coleoptiles and seeds were carried out. Samples of plant tissues were excised, cut into small portions $(2 \times 3 \mathrm{~mm})$ and fixed for $2 \mathrm{~h}$ at $4^{\circ} \mathrm{C}$ in $0.1 \%$ (wt/vol) buffered sodium phosphate and $3 \%$ (wt/vol) glutaraldehyde at $\mathrm{pH} 7.2$. They were then post-fixed with $1 \%$ osmium tetroxide (wt/vol) in the same buffer for $2 \mathrm{~h}$, dehydrated in an ethanol series, and embedded in Epon/Araldite epoxy resin (Electron Microscopy Sciences, Fort Washington, PA, USA). Serial ultrathin sections from each of species were cut with a diamond knife, mounted on copper grids, stained in uranyl acetate and lead citrate, and then observed under a Philips CM 10 (FEI Electron Optics International B.V., Eindhoven, The Netherlands) TEM operating at $80 \mathrm{kV}$.

\section{Cerium content in plant tissues}

Soil samples were digested in a mixture of $96 \%(\mathrm{v} / \mathrm{v}) \mathrm{H}_{2} \mathrm{SO}_{4}$ and $30 \%$ (v/v) $\mathrm{H}_{2} \mathrm{O}_{2}$ in Teflon cylinders for $20 \mathrm{~min}$ at $200^{\circ} \mathrm{C}$ in a microwave (MARS 6; CEM Corp., Matthews, NC, USA). After digestion, samples were diluted 1 to 20 with milliQ water, filtered through $0.45 \mu \mathrm{m}$ filters
A $\quad$ nm

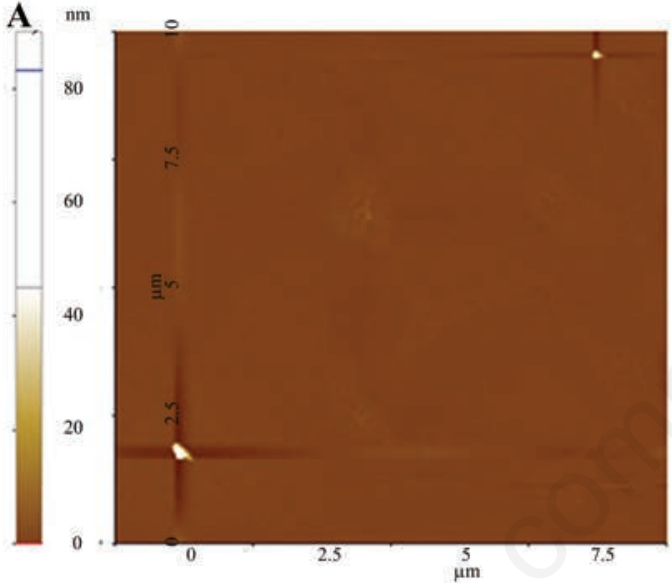

C

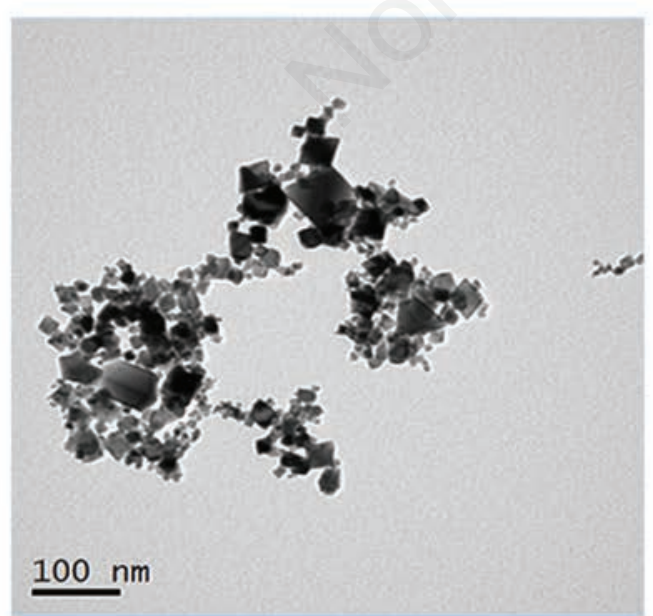

B
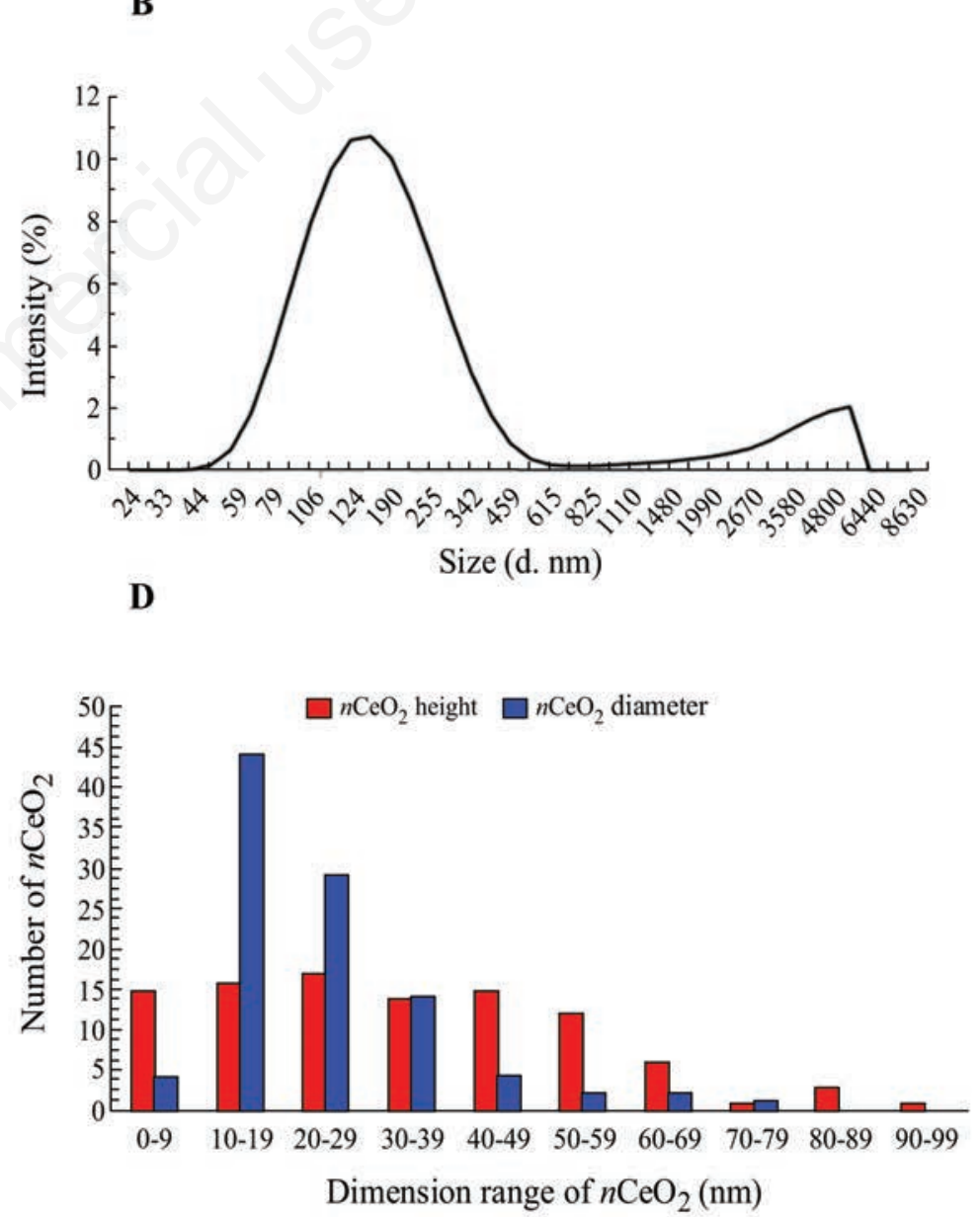

Figure 1. Characterisation of $n \mathrm{CeO}_{2}$ suspension by different techniques: A) topography of a $n \mathrm{CeO}_{2}$ sample area obtained by atomic force microscopy instrument; B) hydrodynamic size distribution (z-average) obtained by dynamic light scattering instrument measured on the base of percentage of light scattered; C) transmission electron microscopy (TEM) image of $n \mathrm{CeO}_{2}$; D) size distributions of $n \mathrm{CeO}_{2}$ obtained by atomic force microscopy $\left(n \mathrm{CeO}_{2}\right.$ height) and TEM $\left(n \mathrm{CeO}_{2}\right.$ diameter). 
and Ce was determined with an ICP-OES (Vista MPX, Varian Inc., Palo Alto, CA, USA). Plant fractions were acid-digested in a microwave oven according to USEPA method 3052 . Plant extracts were filtered $(0.45 \mathrm{~mm}$ politetrafluoroethilene), diluted and analysed. Total Ce in roots, stems and leaves was determined by an ICP-OES whereas Ce concentration in kernels was determined by an ICP-MS (Aurora M90, Bruker Optics, Inc., Billerica, MA, USA).

\section{Data analysis}

Both laboratory and greenhouse studies were arranged in a completely randomised design. Data were tested for homoscedasticity and normality using the Barlett's test and the Shapiro-Wilk test, respectively. Analysis of variance was conducted with a one-way analysis of variance. Tukey's multiple comparison test at $0.05 \mathrm{P}$ level was used to compare means. Statistical analysis was performed using the SPSS program (ver. 17; SPSS Inc., Chicago, IL, USA).

\section{Results}

\section{Characterisation of $n \mathrm{CeO}_{2}$}

The specific surface area of $n \mathrm{CeO}_{2}$ was $46.1 \mathrm{~m}^{2} \mathrm{~g}^{-1}$. The z-average size of the $n \mathrm{CeO}_{2}$ suspension was $174.3 \pm 1.2 \mathrm{~nm}$ (Figure 1B) with a polydispersity index (PDI) value of 0.339 and zeta potential of $0.027 \mathrm{mV}$.
The PDI gives information about the suspension heterogeneity; the value of this parameter resulted lower than 0.7 , which is representative of a solution with a very narrow size distribution. The zeta potential gives information about the stability of the suspension. In our case the value of zeta potential was comprised in the range of instability $(-30 /+30 \mathrm{mV})$.

The height distribution of $n \mathrm{CeO}_{2}$ suspension obtained with the AFM (Figure 1A and C) had an average value of $32.6 \pm 20.7 \mathrm{~nm}$, the first and second quartile include the nanoparticles with an height lower than $29 \mathrm{~nm}$ and the other two quartiles include the ones with an height until $90 \mathrm{~nm}$.

The diameter distribution of $n \mathrm{CeO}_{2}$ in suspension (Figure 1C) had an average value of $22.7 \pm 12.7 \mathrm{~nm}$, the first and second quartile included the nanoparticles with a diameter lower than $19 \mathrm{~nm}$, the third quartile the nanoparticles lower than $29 \mathrm{~nm}$ and the last quartile nanoparticles with a maximum diameter of $79 \mathrm{~nm}$ (Figure 1D).

The results indicated the existence of different size classes of nanoparticles in the suspension. In fact, the average size diameter obtained from the DLS analysis was higher than the value obtained from the TEM analysis. Such difference was likely due to the fact the DLS measures the hydrodynamic diameter of nanoparticles and the tendency of the $n \mathrm{CeO}_{2}$ in suspension to form agglomerates. The values obtained from the AFM and TEM analyses are comparable, although the dimensions analysed are different. The only difference was the distribution: the diameter of nanoparticles resulted to have a narrower distribution than the height.

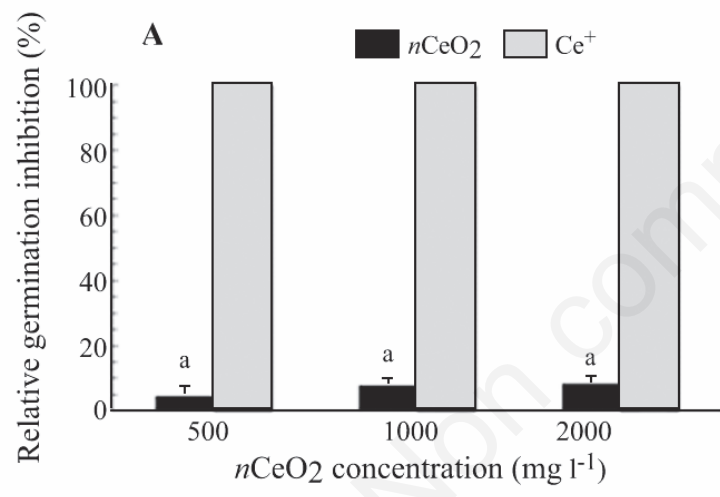

C

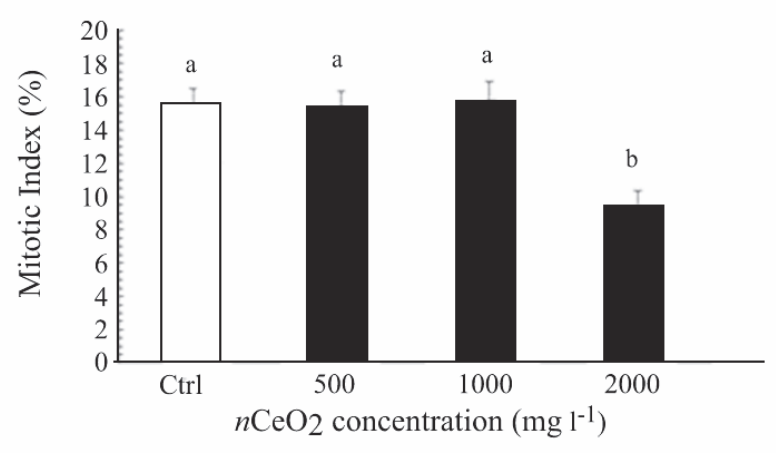

B

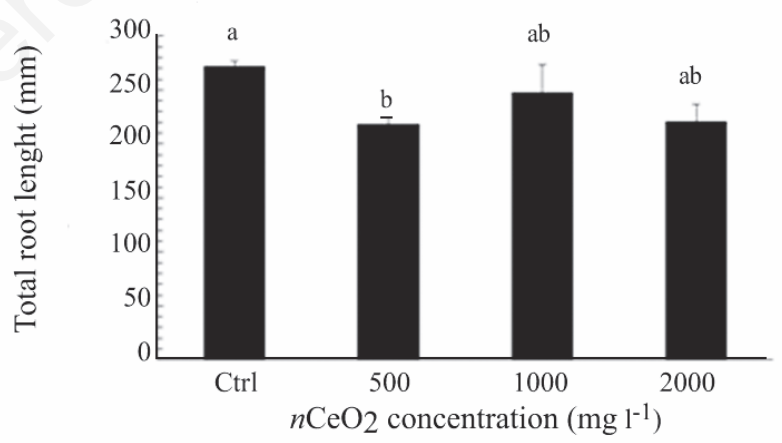

D

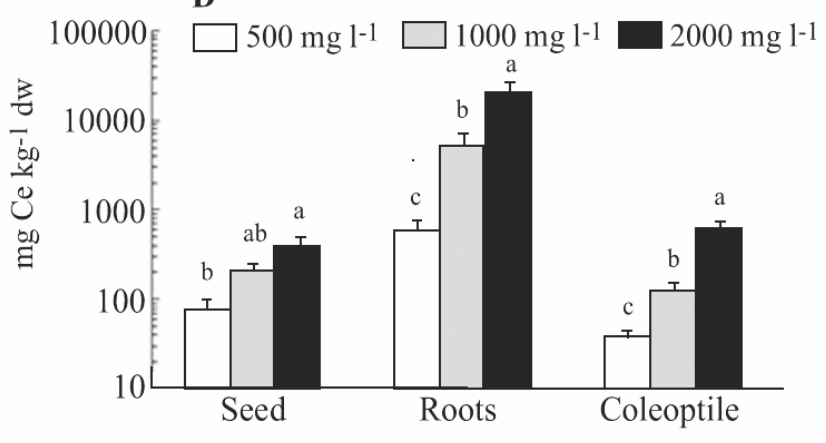

Figure 2. Effects of $n \mathrm{CeO}_{2}$ on seedlings of Hordeum vulgare. A) Relative germination inhibition (\%) observed in seeds treated with $n \mathrm{CeO}_{2}$ and $\left.\mathrm{Ce}^{+} ; \mathrm{B}\right)$ total root length [mean \pm standard error $(\mathrm{SE}) ; \mathrm{n}=3$ ] measured in $n \mathrm{CeO}_{2}$ treated seedlings; $\left.\mathrm{C}\right)$ mitotic index $(\%)$ $($ mean $\pm S E ; n=3)$ observed in root tips of $n \mathrm{CeO}_{2}$ treated seedlings; $\left.\mathrm{D}\right)$ concentration of $\mathrm{Ce}$ in seed, roots and coleoptile $(\mathrm{mean} \pm \mathrm{SE} ; \mathrm{n}=3$ ) of $n \mathrm{CeO}_{2}$ barley treated seedlings. Different letters indicate statistical difference between treatments at Tukey's test $(P<0.05)$. Ctrl, control soil. 


\section{Early growth of barley}

\section{Germination and root development}

The influence of both $n \mathrm{CeO}_{2}$ and ionic $\mathrm{Ce}$ on barley germination was expressed as percentage of inhibition of germination with respect to the control plants (Figure 2A). The different form of Ce influenced differently the process of germination. Cerium in ionic form totally suppressed the seed germination also at the lowest level of concentration. Contrarily, when Ce was supplied as $n \mathrm{CeO}_{2}$, even at the highest level of concentration ( $2000 \mathrm{mg} \mathrm{L}^{-1}$ ), barley germination was not affected since the germination inhibition was negligible (Figure 2A). The cumulated length of roots for each seed is shown in Figure 2B. We expected a negative dose response in the root length. This did not occur, since it was recorded a significantly lower root length at $500 \mathrm{mg} \mathrm{L}^{-1} n \mathrm{CeO}_{2}$ compared to controls (Figure 2B).

\section{Mitotic index}

Figure $2 \mathrm{C}$ reports data of MI, which was used as an indicator of genotoxicity. As plant roots grow, the cell division is usually very fast in the apical meristem of root tips. In our case, the root exposition to 500 and $1000 \mathrm{mg} \mathrm{L}^{-1} n \mathrm{CeO}_{2}$ did not affect the MI, which was not statistically different than control plants. Only the highest dose of $n \mathrm{CeO}_{2}(2000 \mathrm{mg}$ $\mathrm{L}^{-1}$ ) determined a significant reduction of MI with respect to the control (-39\%) (Figure 2C).

\section{Cerium in seedlings}

The concentration of total Ce in the tissues of barley seedlings is showed in Figure 2D. A clear dose-response was recorded in the accumulation of $\mathrm{Ce}$, since Ce concentration in the seedling fractions increased with the increasing of the Ce exposure concentration. As expected, Ce accumulated much more within root tissues than in the coleoptile $(\mathrm{P}<0.05)$. The root-to-coleoptile $\mathrm{Ce}$ translocation factors were $0.074,0.030$ and 0.034 for 500,1000 and $2000 \mathrm{mg} \mathrm{L}^{-1} n \mathrm{CeO}_{2}$ treatments, respectively.

\section{Cerium oxide nanoparticles in seedling tissues}

Several clusters of nanoparticles were found in cortical parenchymal tissues of roots (Figure 3) at both concentrations. Clusters were also observed in the xylem, even if in minor extent (not shown). Energy-dispersive X-ray microanalysis (data not shown) allowed the identification of the clusters as aggregates of $n \mathrm{CeO}_{2}$. No nanoparticles have been detected in the shoots and in the seeds of Ce-treated plantlets, at both concentrations. The ultrastructure of all observed tissues appeared preserved. Neither necrosis, nor damage to the membranes or other cell modifications has been detected. In general, the cell compartments were not significantly affected by the treatments, except for the nuclei of parenchymal cells of root and shoot at both concentrations.

\section{Life cycle study}

\section{Plant growth}

In this study we considered the height of plants and the leaf area as representative parameters of plant growth. Plant height was not affected by the $n \mathrm{CeO}_{2}$ treatments. To the contrary, $n \mathrm{CeO}_{2}$ had a strong negative effect on plant vegetative growth (Figure $4 \mathrm{~A}$ ). In fact, the leaf area in $n \mathrm{CeO}_{2}$ treated plants was on average about $36 \%$ lower compared to the control ones. However, considering the effects of the treatments, the greater decrease of leaf area was unexpectedly found in Ce 500 plants where the leaf surface was more than halved than that of the control plants (166 vs $356 \mathrm{~cm}^{2}$ per plant). At the highest concentration of $n \mathrm{CeO}_{2}$, plant leaf area was equal to $288 \mathrm{~cm}^{2}$ per plant (about $-19 \%$ compared to the control).

\section{Leaf photosynthetic rate}

The leaf photosynthetic rate $\left(\mathrm{A}_{\max }\right)$ at three different growth stages (booting, heading, milk maturity) is shown in Figure 4B. Since the shift in phenological stages of barley (Marchiol et al., 2016), the gas exchanges measurements were evaluated by comparing plants at the same phenological phase. We verified that $n \mathrm{CeO}_{2}$ treatments had a statistically significant effect on leaf photosynthesis. At the booting phase, $\mathrm{A}_{\max }$ was positively affected by $500 \mathrm{mg} \mathrm{kg}^{-1} n \mathrm{CeO}_{2}$ compared to control plants $(\mathrm{P} \leq 0.01)$, which in turn had $\mathrm{A}_{\max }$ values similar to $1000 \mathrm{mg}$ $\mathrm{kg}^{-1} n \mathrm{CeO}_{2}$ plants (Figure $4 \mathrm{~B}$ ). In the subsequent phases of the life cycle of barley, $A_{\max }$ declined with no evidence of statistically significant differences between treatments and control.

\section{Cerium uptake and translocation}

The concentration of $\mathrm{Ce}$ in soils with $n \mathrm{CeO}_{2}$ addition, and total $\mathrm{Ce}$ content recorded in plant fractions (roots, stems, leaves, and kernels) are presented in Figure 4C. Note that in Figure 4C a logarithmic scale was used in order to obtain a comprehensive view of the very different Ce concentration reached within the plant fractions. Data on Ce soil concentration confirmed that the $n \mathrm{CeO}_{2}$-soil enrichment was performed correctly. As regards the Ce accumulation in plant fractions, in the pot trial we recorded a clear dose-response in all plant fractions, with the only exception of the kernels that confirmed our observations in the lab experiment. The Ce mean concentration in roots was the highest compared to those of other plant fractions (45.3 and $969 \mu \mathrm{g} \mathrm{kg}^{-1}$ respectively in Ce $500 \mathrm{mg} \mathrm{kg}^{-1}$ and Ce $1000 \mathrm{mg} \mathrm{kg}^{-1}$ plants). As regards Ce concentration in stems and leaves, we observed less evident differences among the treatments. Moreover, the stem-to-leaf translocation ratio ranged between 1.14 (Ctrl) and 1.72 (Ce 1000), indicating that the process of Ce accumulation in leaves takes place without being significantly affected by

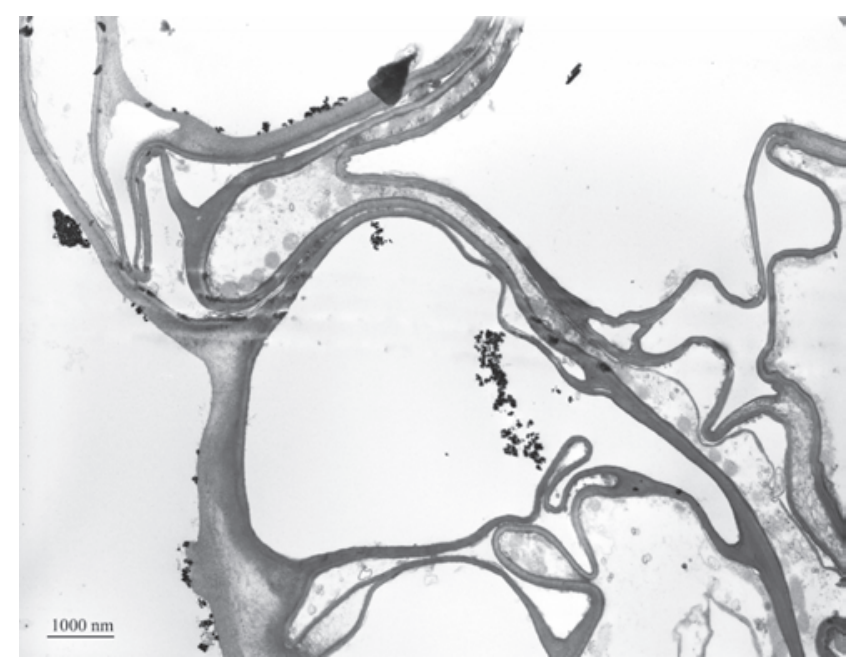

Figure 3. Representative transmission electron microscopy micrograph of electron dense precipitates recovered in root tissues of Hordeum vulgare exposed to treatment with $n \mathrm{CeO}_{2}$. Big aggregates of nanoparticles are visible in the cortical parenchymal cells. 
the treatments. The highest Ce concentration in leaves was recorded in Ce 1000 plants (3027 $\mu \mathrm{g} \mathrm{kg}^{-1}$ ). No statistically significant differences among the treatments were recorded (Figure 4C).

\section{Macronutrient contents of barley kernels}

The accumulation of calcium (Ca), potassium (K), phosphorus (P) and sulphur (S) in barley kernels harvested from $n \mathrm{CeO}_{2}$ treated plants and control ones is showed in Figure 4D. It was never found an increase in concentration of the elements in plants treated with $n \mathrm{CeO}_{2}$ with respect to the control plants. The accumulation of $\mathrm{Ca}$ and $\mathrm{P}$ in kernels was unaffected by the $n \mathrm{CeO}_{2}$ treatments. The values of concentration are comprised between 377 and $462 \mathrm{mg} \mathrm{kg}^{-1}$ and between 4511 and $4549 \mathrm{mg} \mathrm{kg}^{-1}$, respectively for Ca and P (Figure 4D). In the case of $\mathrm{K}$, the accumulation in kernel tissues was significantly lowered by both $n \mathrm{CeO}_{2}$ treatments compared to control $(\mathrm{P} \leq 0.005)$. However, no significant difference was recorded between the treatments. In the case of $S$ concentrations in kernels of treated plants were significantly lower $(\mathrm{P}<0.05)$ than the untreated samples by 12 and $24 \%$, respectively for $\mathrm{Ce}$ 500 and Ce 1000 plants (Figure 4D).

\section{Cerium oxide nanoparticles in plant tissues}

To verify the uptake and subsequent translocations of $n \mathrm{CeO}_{2}$ from roots to aerial plant fractions, ultrastructural analyses on plant leaf tissues were carried out. Rare clusters of nanoparticles were found in leaves sampled from plants grown in $n \mathrm{CeO}_{2}$ soil enriched (Figure 5). Nanoparticles were observed in parenchyma leaf tissues, in the stroma of the chloroplast and in the vacuoles.
Despite the treatment, the chloroplast ultrastructure appeared normal, with preserved ultrastructure, and, in general, all the cell compartments of the chlorophyll parenchyma did not appear significantly affected. This evidence was in agreement with phenotypical/morphological analyses, as we did not observe macroscopic cell death at the tissue level after the $n \mathrm{CeO}_{2}$ treatments. Nevertheless, in the vascular tissue, some ultrastructural modifications were visible, especially those affecting the cellular organelles: some nuclei showed condensed chromatin and mitochondria with swollen cristae (not shown).

\section{Discussion}

\section{Germination and early growth of barley}

Since nanotoxicology is still in its infancy, we lack standardised experimental protocols. This implies that experimental data found in literature in some cases appeared contradictory. Our data provide a clear example thereof. In fact, in our conditions according to Rico et al. (2014) the germination of barley was unaffected by $500-2000 \mathrm{mg} \mathrm{L}^{-1}$ $n \mathrm{CeO}_{2}$. However, such results are at odds with the results reported by López-Moreno et al. (2010). It is well known that the behaviour of metal nanoparticles is strongly influenced by their physical-chemical properties (Nowack and Bucheli, 2007). So, in this case it is likely that contradictory results are simply due to the use of particles of different size. The size of nanoparticles influences their zeta potential. In this case, this promotes the agglomeration of $n \mathrm{CeO}_{2}$ that brings to a low bioavail-
A
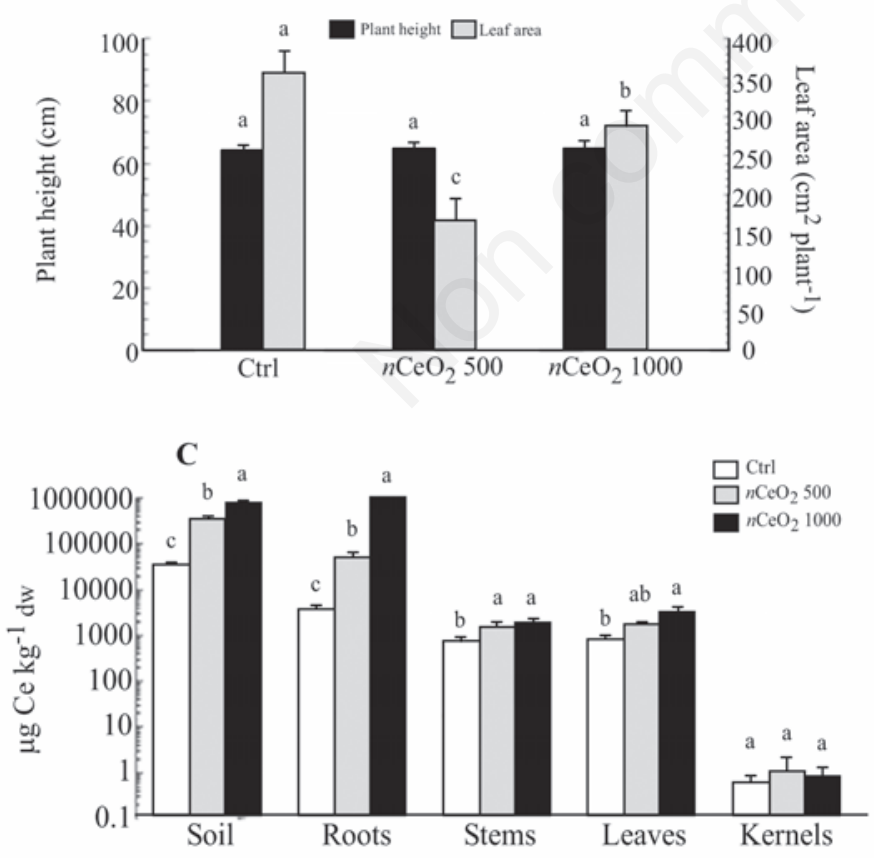

B
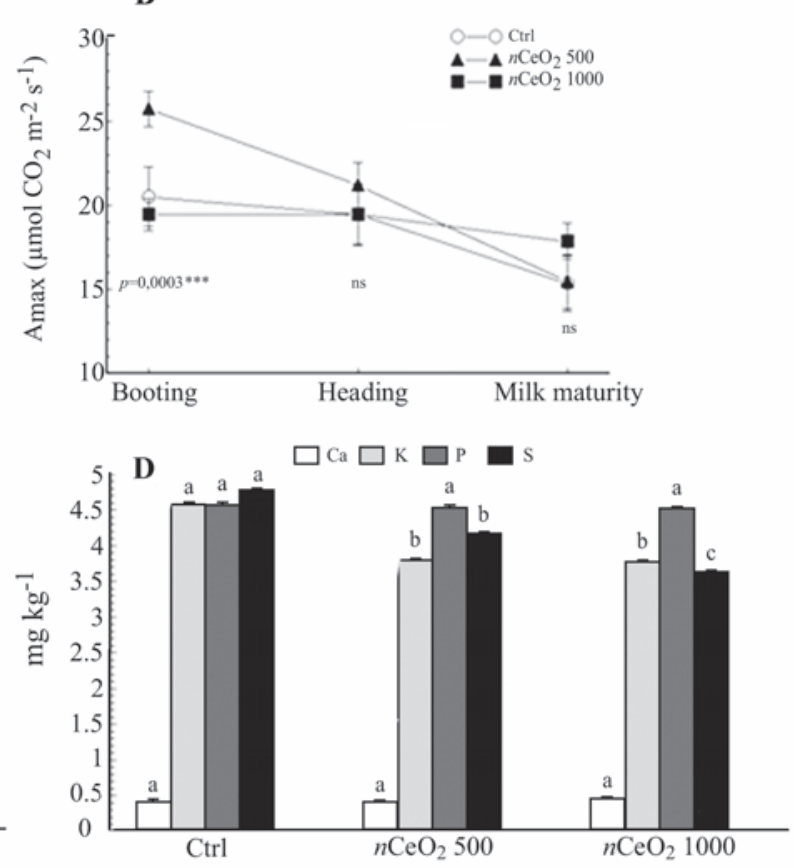

Figure 4. Effects of $n \mathrm{CeO}_{2}$ on adult plants of Hordeum vulgare. A) Plant height and leaf area observed in plants of $H$. vulgare grown in control (Ctrl) soil and $n \mathrm{CeO}_{2}$ amended soils; B) leaf photosynthetic rate at saturating light intensity, recorded at three different phenological stages (booting, heading and milk maturity) in leaves of barley plants grow in $\mathrm{Ctrl}$ and $n \mathrm{CeO}_{2}$ amended soils; $\mathrm{C}$ ) $\mathrm{Ce}$ concentration [mean \pm standard error $(\mathrm{SE}) ; \mathrm{n}=5$ ] observed in soil, roots, stems, leaves and kernels of $H$. vulgare grown in $\mathrm{Ctrl}_{\text {soil }}$ and $n \mathrm{CeO}{ }_{2}$ amended soils; D) macronutrient concentrations in barley kernels at ripening from main shoot of plants grown $\mathrm{Ctrl}_{\text {and }} n \mathrm{CeO}_{2}$ amended soils. Bars are mean \pm SE $(n=5)$. Different letters indicate statistical difference between treatments at Tukey's test $(P<0.05)$. 
ability and absence of phytotoxic effects on treated seeds.

We were rather surprised that the root elongation in Ce 500 plants was lower than in Ce 1000 ones. The same evidence was recorded for barley leaf area. Such apparent paradox is very likely due to aggregation processes (indicated by DLS and DCS analyses), which occurred between Ce nanoparticles in soil treated with the higher dose of $n \mathrm{CeO}_{2}$. The presence of more aggregated Ce nanostructures results in a lesser bioavailable $n \mathrm{CeO}_{2}$. According to Calabrese and Baldwin (2003) hormesis is the nonlinear dose-response relationship in which low versus high doses of a given agent or stressor can exert effects in opposite directions. Hormesis is commonly reported to occur in plants as adaptive response to non-essential trace metals and metalloids (Poschenrieder et al., 2013) as well as metal nanoparticles (Nascarella and Calabrese, 2012; Bell et al., 2014).

\section{Barley life cycle and cerium accumulation}

The potential benefits of nanotechnologies in agriculture are yet to be realised since they are still moving from theoretical knowledge towards the field applications. Currently, little is known either about life cycle of nanomaterials in the agroecosystem or their interactions with the biota it is possible that ENMs may represent an emerging class of contaminants (Gardea-Torresdey et al., 2014).

A number of papers, reporting the effects of crop exposure to metal nanoparticles (MeNPs), have been published (Miralles et al., 2012; Rico et al., 2011) so far. Among these, only a few reported observations conducted on plants grown in real soil. This can be largely explained by the very complex dynamics of MeNPs in soil, which have not been yet fully clarified. In fact, it was verified that soil $\mathrm{pH}$, organic matter content, texture and cation exchange capacity strongly influence the fate of nanomaterials in soil (Cornelis et al., 2014; Schlich and Hund-Rinke, 2015).

The main goal of this work was not to study the soil behaviour of MeNPs, but to check if the presence in the soil of these materials determined some effects on plant growth, on Ce accumulation in plant tissues, and other disturbances. Our data suggested that soil Ce was able to reach the plant leaves by moving through the vascular system. However, only a small amount of Ce was able to reach the aboveground crop biomass. The Ce concentration in the kernels was three-four orders of magnitude lower than those recorded in plant leaves (range 0.50-0.87 $\mu \mathrm{g} \mathrm{kg}-1$ ).

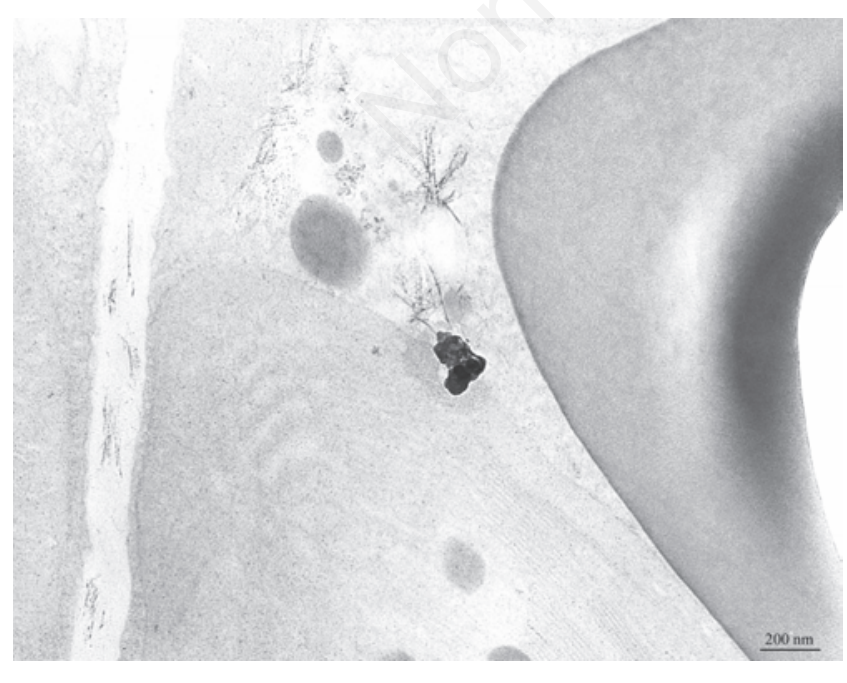

Figure 5. Transmission electron microscopy micrograph showing particle aggregates in the proximity of the chloroplast in a leaf of Hordeum vulgare. The ultrastructure seems to be not affected by the treatment.
These findings are in agreement with those provided by Priester et al. (2012), Zhao et al. (2013) and Rico et al. (2014), respectively on soybean, cucumber, and wheat. With regard to the consequences on plant growth, in this paper we reported that the plant height was not affected by the $n \mathrm{CeO}_{2}$ treatments, whereas the leaf area was lowered in plants grown in the $n \mathrm{CeO}_{2}$ enriched soils. Our data partially agree with the findings by Priester et al. (2012) in Glycine max. Zhao et al. (2013) did not observe negative effects on biometric parameters in plants of Cucumis sativum with $n \mathrm{CeO}_{2}$. On the opposite, Rico et al. (2015) reported that $n \mathrm{CeO}_{2} 500 \mathrm{mg} \mathrm{kg}^{-1}$ increased the height of barley plants and promoted the accumulation of DM in plant shoots.

Some papers demonstrated that, due to their small size, ENMs might pass biological barriers and induce physiological, biochemical and genetic modifications in plants (Gardea-Torresdey et al., 2014). Therefore, a further potentially negative effect concerns the modifications on crop nutritional content, which in turn is strongly related with food nutraceutical properties and human health. For this reason, we focused on both Ce and macronutrient accumulation in barley kernels. In agreement with the findings from López-Moreno et al. (2010), Zhao et al. (2015), and Rico et al. (2015), we did not observe any significant difference among the treatments for kernel Ce concentrations. Our results suggest that translocation of $n \mathrm{CeO}_{2}$ into barley kernels is rather unlikely. With regard to the macronutrients, we recorded variations in the kernel concentration of $\mathrm{K}$ and $\mathrm{S}$, in $n \mathrm{CeO}_{2}$ treated plants compared to control ones. This suggests that the presence of nanoscale cerium oxide is able to influence plant metabolism during seed maturation, inducing a breakdown of homeostasis of $\mathrm{K}$ and $\mathrm{S}$. Such elements have a remarkable role in plant metabolism. In cell metabolism $\mathrm{K}$ is involved in protein synthesis, in maintaining the osmotic potential, and controlling the $\mathrm{pH}$ equilibrium (Marschner, 1995). The reduction of $\mathrm{K}$ concentration in the kernels of $n \mathrm{CeO}_{2}$ treated plants could have a negative impact on enzyme activities and, therefore, on kernel quality. Sulphur is a structural constituent of both coenzymes and products of secondary metabolism (Marschner, 1995). A reduction of $S$ could negatively affect the glutathione synthesis and the antioxidant capacity of kernels. Our results on $\mathrm{S}$ are in agreement with the evidences provided by Rico et al. (2014) who, beyond a negative $n \mathrm{CeO}_{2}$ dose effect on $\mathrm{S}$ concentration in rice grains, observed also a cultivar response. On the opposite, PeraltaVidea et al. (2014) reported no significant effects on $\mathrm{S}$ and $\mathrm{K}$ content in soybean pods from $n \mathrm{CeO}_{2}$ treated plants.

\section{Conclusions}

Our findings on the effects of $n \mathrm{CeO}_{2}$ suspensions on the early growth of barley evidenced that seed germination was not affected by the $n \mathrm{CeO}_{2}$ suggesting that $n \mathrm{CeO}_{2}$ were impeded to entering the seed coatings. We also verified that the root-to-coleoptile Ce translocation was dose-dependent. Moreover, signals of genotoxicity were evidenced by mitotic index coupled with a shortage of root elongation.

In adult plants, although no symptoms of toxicity have been detected in plants, we demonstrated that growth of barley was affected by $n \mathrm{CeO}_{2}$. All plants concluded their life cycle producing seeds. In treated plants, we verified differences in some biometric parameters compared to the control ones. However, the Ce uptake and translocation were minute both in the aerial plant fraction and in the seeds.

Although investigations on the effects of nanoparticles in plants continue to increase, there are still many unresolved issues and challenges, in particular at the biota-nanomaterial interface (Nowack et al., 2015). In fact, several exciting aspects should be explored, such as the biotransformation of nanoparticles within plant tissues, the interactions between nanoparticles and plant metabolism, as well as the con- 
sequences of plant chronic exposure to low/high nanoparticle concentrations.

Studies on relations between nanomaterials and plants are still in an initial phase. For now, we only know which tools to use to investigate at the nanoscale. There will be plenty to do to find out everything that is going on down there, exactly as Richard Feynman (1960) predicted 56 years ago.

\section{References}

Aksoy Ö, Deveci A, 2012. The investigation of the cytotoxic effects of some pesticides on soybean (Glycine max L.). Cytologia 77:475-83.

Bell IR, Ives JA, Jonas WB, 2014. Nonlinear effects of nanoparticles: biological variability from hormetic doses, small particle sizes, and dynamic adaptive interactions. Dose Resp. 12:202-32.

Calabrese EJ, Baldwin LA, 2003. The hormetic dose-response model is more common than the threshold model in toxicology. Toxicol. Sci. 71:246-50.

Collin B, Auffan M, Johnson AC, Kaur I, Keller AA, Lazareva A, Lead JR, Ma X, Ruth C, Merrifield RC, Svendsen C, White JC, Unrine JM, 2014. Environmental release, fate and ecotoxicological effects of manufactured ceria nanomaterials. Environ. Sci. Nano 1:533.

Cornelis G, Hund-Rinke K, Kuhlbusch T, van den Brink N, Nickel C, 2014. Fate and bioavailability of engineered nanoparticles in soils: a review. Crit. Rev. Env. Sci. Technol. 44:2720-64.

Dasgupta N, Ranjan S, Mundekkad D, Ramalingam C, Shanker R, Kumar A, 2015. Nanotechnology in agro-food: from field to plate. Food Res. Int. 69:381-400.

FAOSTAT, 2014. Food and Agriculture Organization of the United Nations - Food and agricultural commodities production: commodities by regions. Available from: faostat3.fao.org/download/Q/QC/E Accessed: 19 September 2016.

Feynman RP, 1960. There's plenty of room at the bottom. Eng. Sci. 23:22-36.

Gardea-Torresdey JL, Rico CM, White JC, 2014. Trophic transfer, transformation and impact of engineered nanomaterials in terrestrial environments. Env. Sci. Technol. 48:2526-40.

Hernández-Viezcas JA, Castillo-Michel H, Cooke Andrews J, Cotte M, Rico C, Peralta-Videa JR, Ge Y, Priester JH, Holden PA, GardeaTorresdey JL, 2013. In situ synchrotron $\mathrm{X}$ ray fluorescence mapping and speciation of $\mathrm{CeO} 2$ and $\mathrm{ZnO}$ nanoparticles in soil cultivated soybean (Glycine max). ACS Nano 7:1415-23.

Keller A, McFerran S, Lazareva A, Suh S, 2013. Global life cycle releases of engineered nanomaterials. J. Nanopart. Res. 15:1692.

López-Moreno ML, de La Rosar G, Hernández-Viezcas JA, Peralta-Videa JR, Gardea-Torresdey JL 2010. X-ray absorption spectroscopy (XAS) corroboration of the uptake and storage of $\mathrm{CeO}_{2}$ nanoparticles and assessment of their differential toxicity in four edible plant species. J. Agric. Food Chem. 58:3689-93.

Lowry GV, Gregory KB, Apte SC, Lead JR, 2012. Transformations of nanomaterials in the environment. Environ. Sci. Technol. 46: 6893-9.

Ma Y, Kuang L, He X, Bai W, Ding Y, Zhang Z, Zhao Y, Chai Z, 2010. Effects of rare earth oxide nanoparticles on root elongation of plants. Chemosphere 78:273-9.

Marchiol L, Mattiello A, Poš i F, Fellet G, Zavalloni C, Carlino E, Musetti $\mathrm{R}, 2016$. Phenology and physiology of Hordeum vulgare L. as affected by $\mathrm{CeO}_{2}$ and $\mathrm{TiO}_{2}$ nanoparticles. Int. J. Environ. Res. Public Health 13:332.

Marschner H, 1995. Mineral nutrition of higher plants. $2^{\text {nd }}$ ed. Academic Press, Cambridge, MA, USA.

Mattiello A, Filippi A, Poš i F, Musetti R, Salvatici MC, Giordano C,
Vischi M, Bertolini A, Marchiol L, 2015. Evidence of phytotoxicity and genotoxicity in Hordeum vulgare $\mathrm{L}$. exposed to $\mathrm{CeO}_{2}$ and $\mathrm{TiO}_{2}$ nanoparticles. Front. Plant Sci. 6:1043.

Miralles P, Church TL, Harris AT, 2012. Toxicity, uptake, and translocation of engineered nanomaterials in vascular plants. Environ. Sci. Technol. 46: 9224-9239.

Morales MI, Rico CM, Hernández-Viezcas JA, Nunez JE, Barrios AC, Tafoya A, Flores-Marges JP, Peralta-Videa JR, Gardea-Torresdey JL, 2013. Toxicity assessment of cerium oxide nanoparticles in cilantro (Coriandrum sativum L.) plants grown in organic soil. J. Agric. Food Chem. 61:6224-30.

Nascarella MA, Calabrese EJ, 2012. A method to evaluate hormesis in nanoparticle dose-response. Dose Resp. 10:344-54.

Nowack B, Bucheli TD, 2007. Occurrence, behavior and effects of nanoparticles in the environment. Environ. Pollut. 150:5-22.

Nowack B, Baalousha M, Bornhöft N, Chaudhry 0, Cornelis G, Cotterill J, Gondikas A, Hassellöv M, Lead J, Mitrano DM, von der Kammer F, Wontner-Smith T, 2015. Progress towards the validation of modelled environmental concentrations of engineered nanomaterials by analytical measurements. Environ. Sci. Nano, Nano 2:421-8.

Peralta-Videa JR, Hernández-Viezcas JA, Zhao L, Corral Diaz B, Ge Y, Priester JH, Holden PA, Gardea-Torresdey JL, 2014. Cerium dioxide and zinc oxide nanoparticles alter the nutritional value of soil cultivated soybean plants. Plant Physiol. Biochem. 80:128-35.

Poschenrieder C, Cabot C, Martos S, Gallego B, Barceló J, 2013. Do toxic ions induce hormesis in plants? Plant Sci. 212:15-25.

Priester JH, Ge Y, Mielke RE, Horst AM, Moritz SC, Espinosa K, Gelb J, Walker SL, Nisbet RM, An YJ, Schimel JP, Palmer RG, HernandezViezcas JA, Zhao L, Gardea-Torresdey JL, Holden PA, 2012. Soybean susceptibility to manufactured nanomaterials with evidence for food quality and soil fertility interruption. Proc. Natl. Acad. Sci. U. S. A. 109:E2451-6.

Richardson SD, Ternes TA, 2011. Water analysis: emerging contaminants and current issues. Anal. Chem. 83:4614-48.

Rico CM, Majumdar S, Duarte-Gardea M, Peralta-Videa J.R, GardeaTorresdey JL, 2011. Interaction of nanoparticles with edible plants and their possible implications in the food chain. J. Agric. Food Chem. 59: 3485-3498.

Rico C, Morales M, Barrios A, McCreary R, Hong J, Lee W-Y, Nunez J, Peralta-Videa JR, Gardea-Torresdey JL, 2013. Effect of cerium oxide nanoparticles on the quality of rice (Oryza sativa L.) grains. J. Agric. Food Chem. 61: 11278-11285.

Rico CM, Lee SC, Rubenecia R, Mukherjee A, Hong J, Peralta-Videa JR, Gardea-Torresdey JL, 2014. Cerium oxide nanoparticles impact yield and modify nutritional parameters in wheat (Triticum aestivum L.). J. Agric. Food Chem. 62:9669-75.

Rico CM, Peralta-Videa JR, Gardea-Torresdey JL, 2015. Differential effects of cerium oxide nanoparticles on rice, wheat, and barley roots: A Fourier Transform Infrared (FT-IR) microspectroscopy study. Appl. Spectrosc. 69: 287-295.

Salminen R, Batista MJ, Bidovec M, Demetriades A, De Vivo B, De Vos W, Duris M, Gilucis, A, Gregorauskiene V, Halamic J, Heitzmann P, Lima A, Jordan G, Klaver G, Klein P, Lis J, Locutura J, Marsina K, Mazreku A, 0'Connor PJ, Olsson SÅ, Ottesen RT, Petersell V, Plant JA, Reeder S, Salpeteur I, Sandström H, Siewers U, Steenfelt A, Tarvainen T, 2005. Geochemical atlas of Europe. Part 1 Background information, methodology and maps. Geological Survey of Finland, Espoo, Finland.

Schlich K, Hund-Rinke K, 2015. Influence of soil properties on the effect of silver nanomaterials on microbial activity in five soils. Env. Poll. 196:321-30.

Schneider CA, Rasband WS, Eliceiri KW, 2012. NIH Image to ImageJ: 25 years of image analysis. Nat. Methods 9:671-5. 
Tyler G, 2004. Rare earth elements in soil and plant systems - a review. Plant Soil 267:191-206.

USEPA (U.S. Environmental Protection Agency), 2007. Nanotechnology white paper - external review draft. EPA 100/B-07/001. Available from: https://www.epa.gov/osa/nanotechnology-white-paper

Wang Q, Ebbs SD, Chen Y, Ma X, 2013. Trans-generational impact of cerium oxide nanoparticles on tomato plants. Metallomics 5:753-9.

Zhang P, Ma Y, Zhang Z, He X, Zhang J, Guo Z, Tai R, Zhao Y, Chai Z, 2012. Biotransformation of ceria nanoparticles in cucumber plants. ACS Nano 6:9943-50.

Zhao H, Zhou Q, Zhou M, Li C, Gong X, Liu C, Qu C, Wang L, Si W, Hong F, 2012. Magnesium deficiency results in damage of nitrogen and carbon cross talk of maize and improvement by cerium addition.
Biol. Trace Elem. Res.148:102-9.

Zhao L, Sun Y, Hernández-Viezcas JA, Servin AD, Hong J, Niu G, Peralta-Videa JR, Duarte-Gardea M, Gardea-Torresdey JL, 2013. Influence of $\mathrm{CeO}_{2}$ and $\mathrm{ZnO}$ nanoparticles on cucumber physiological markers and bioaccumulation of Ce and Zn: a life cycle study. J. Agric. Food Chem. 61:11945-51.

Zhao L, Sun Y, Hernández-Viezcas JA, Hong J, Majumdar S, Niu G, Duarte-Gardea M, Peralta-Videa JR, Gardea-Torresdey JL, 2015. Monitoring the environmental effects of $\mathrm{CeO}_{2}$ and $\mathrm{ZnO}$ nanoparticles through the life cycle of corn (Zea mays) plants and in situ $\mu$ XRF mapping of nutrients in kernels. Environ. Sci. Technol. 49:2921-8. 